\title{
Video Article \\ Synthesis of Soft Polysiloxane-urea Elastomers for Intraocular Lens Application
}

\author{
Natascha Riehle ${ }^{*^{1,2}}$, Sibylle Thude ${ }^{{ }^{3}}$, Andreas Kandelbauer ${ }^{1,2}$, Günter E. M. Tovar ${ }^{3,4}$, Günter Lorenz ${ }^{1,2}$ \\ ${ }^{1}$ Reutlingen Research Institute, Reutlingen University \\ ${ }^{2}$ School of Applied Chemistry, Reutlingen University \\ ${ }^{3}$ Fraunhofer-Institute for Interfacial Engineering and Biotechnology IGB \\ ${ }^{4}$ Institute of Interfacial Process Engineering and Plasma Technology IGVP, University of Stuttgart \\ *These authors contributed equally
}

Correspondence to: Günter Lorenz at guenter.lorenz@reutlingen-university.de

URL: https://www.jove.com/video/58590

DOI: doi: $10.3791 / 58590$

Keywords: Chemistry, Issue 145, Segmented polysiloxane-urea elastomers, polydimethylsiloxane, ring-chain equilibration, refractive index, mechanical properties, mechanical hysteresis, cell viability, biomedical application

Date Published: 3/8/2019

Citation: Riehle, N., Thude, S., Kandelbauer, A., Tovar, G.E., Lorenz, G. Synthesis of Soft Polysiloxane-urea Elastomers for Intraocular Lens Application. J. Vis. Exp. (145), e58590, doi:10.3791/58590 (2019).

\section{Abstract}

This study discusses a synthesis route for soft polysiloxane-based urea (PSU) elastomers for their applications as accommodating intraocular lenses (a-IOLs). Aminopropyl-terminated polydimethylsiloxanes (PDMS) were previously prepared via the ring-chain equilibration of the cyclic siloxane octamethylcyclotetrasiloxane $\left(D_{4}\right)$ and 1,3-bis(3-aminopropyl)-tetramethyldisiloxane (APTMDS). Phenyl groups were introduced into the siloxane backbone via the copolymerization of $D_{4}$ and 2,4,6,8-tetramethyl-2,4,6,8-tetraphenyl-cyclotetrasiloxane $\left(D_{4}{ }^{\text {Me,Ph }}\right)$. These polydimethylmethyl-phenyl-siloxane-block copolymers were synthesized for increasing the refractive indices of polysiloxanes. For applications as an a-IOL, the refractive index of the polysiloxanes must be equivalent to that of a young human eye lens. The polysiloxane molecular weight is controlled by the ratio of the cyclic siloxane to the endblocker APTMDS. The transparency of the PSU elastomers is examined by the transmittance measurement of films between 200 and $750 \mathrm{~nm}$, using a UV-Vis spectrophotometer. Transmittance values at $750 \mathrm{~nm}$ (upper end of the visible spectrum) are plotted against the PDMS molecular weight, and $>90 \%$ of the transmittance is observed until a molecular weight of 18,000 $\mathrm{g} \cdot \mathrm{mol}^{-1}$. Mechanical properties of the PSU elastomers are investigated using stress-strain tests on die-cut dog-bone-shaped specimens. For evaluating mechanical stability, mechanical hysteresis is measured by repeatedly stretching (10x) the specimens to $5 \%$ and $100 \%$ elongation Hysteresis considerably decreases with the increase in the PDMS molecular weight. In vitro cytotoxicity of some selected PSU elastomers is evaluated using an MTS cell viability assay. The methods described herein permit the synthesis of a soft, transparent, and noncytotoxic PSU elastomer with a refractive index approximately equal to that of a young human eye lens.

\section{Video Link}

The video component of this article can be found at https://www.jove.com/video/58590/

\section{Introduction}

Senile cataract, affecting the age group of $\geq 60$ years, leads to the advanced opacification of the natural crystalline lens. This age-related condition is probably caused by oxidative changes that are accelerated by UV irradiation ${ }^{1,2,3}$. Conventional treatment for senile cataract involves the surgical extraction of the cataractous lens, followed by the implantation of an artificial intraocular lens (IOL) into an empty lens capsule via an injection system ${ }^{2}$. However, a majority of IOLs are manufactured from acrylic polymers (hydrophobic and hydrophilic acrylate or methacrylate polymers) with extremely rigid structures; hence, the eye loses its ability to accommodate to various distances ${ }^{2,4}$. Therefore, patients with monofocal IOL implants are dependent on spectacles for near vision (e.g., while reading a newspaper or a book) ${ }^{5}$.

Different approaches to restoring the accommodation ability after cataract surgery have been reported. Among these approaches, two principal strategies can be distinguished: refilling the empty lens capsule by injecting a liquid or gel-like polymers and developing soft, foldable a-IOLs ${ }^{6,7,8}$. The concept of "lens refilling" is promising because gels can be prepared with Young's moduli as low as those of the natural human eye lens (ca. $1-2 \mathrm{kPa})^{9}$; however, this approach is still experimental ${ }^{8}$, and studies are only conducted on animal eyes.

Lens capsules have been refilled by implanting inflatable silicone balloons ${ }^{10}$ filled with liquid silicone or by directly injecting silicone ${ }^{11,12}$ that was subsequently cured in the capsule via hydrosilylation. However, issues related to surface wrinkles on the balloons, a lower accommodation amplitude compared to the preoperative state, and the formation of severe secondary cataracts (anterior and posterior capsule opacification) have been noted ${ }^{7,8,12,13}$. In particular, long curing times $(70 \mathrm{~min}-12 \mathrm{~h}$ ) cause an increased risk of leakage into the surrounding eye compartments, leading to postoperative inflammation ${ }^{10,14}$. Therefore, other materials for replacing the crystalline lens are recommended, including hydrogels based on polyethylene glycol diacrylate, acrylate-modified copolymers of vinyl alcohol $(\mathrm{N} \text {-vinylpyrrolidone })^{15}$, methacrylatemodified polysiloxanes ${ }^{16,17}$, poloxamer ${ }^{18}$, and diisocyanate-crosslinked polyalcohols ${ }^{9}$. However, the monomer viscosity (i.e., gel swelling after 
the injection and crosslinking), extremely low or high refractive indices, mechanical stability and integrity, unpredictable postoperative refraction, low accommodation range, and after-cataract formation constitute the main issues ${ }^{6,7,8,9,15,18}$. Commercially, the accommodation ability is mainly restored by developing foldable a-IOLs. Such a-IOLs should provide accommodation by the movement of the IOL optic to the anterior site of the lens capsule via the contraction of the ciliary muscle. Several models have been introduced in the market in 1996, 2001, and 2002 However, during clinical studies, the estimated accommodation amplitudes for those implanted a-IOLs were extremely low ( $\leq 1.5 \mathrm{D})$ to permit unaided reading $(3-4 D)^{6,7,8,19,20}$. Therefore, an a-IOL comprising two connected optics (dual-optic IOL) is being developed for increasing the accommodation range ${ }^{6,21}$. The design of only one lens has been examined for its accommodative performance in human eyes, albeit conflicting results have been reported $22,23,24,25$.

Typically, silicone elastomers are regarded to be biologically inert and nontoxic; therefore, silicone elastomers have a long history of being applied as biocompatible materials in medicine and medical engineering (e.g., in breast implants, craniofacial implants, joint prosthetics, wound dressings, catheters, drains, and shunts) ${ }^{26,27}$. Owing to their softness, transparency, and high oxygen permeability, silicone elastomers also find applications as contact lenses and IOLs ${ }^{2,28,29}$. However, silicones must be covalently crosslinked and often require reinforcing fillers to gain sufficient mechanical integrity. Crosslinking is disadvantageous as it prohibits the subsequent processing of elastomers either by thermoplastic methods (e.g., injection molding) or by processing from solutions (e.g., solvent casting). In contrast, thermoplastic polyurethanes exhibit mechanical stability but are susceptible to degradation within the biological environment, particularly if polyester- or polyether-based macrodiols are used. Therefore, efforts to combine flexibility and hydrolytic or oxidative stability with excellent mechanical properties are concentrated on the incorporation of hydroxyl- or amino-functional PDMS as soft segments into polyurethanes, polyurethane-ureas, and polyureas ${ }^{27}$. To enhance the compatibility of the polar urethane or urea hard segment with a highly nonpolar PDMS soft segment and to improve mechanical properties, different polyether-based macrodiols are incorporated along with PDMS ${ }^{30,31,32}$. Particularly, the Thilak Gunatillake group has systematically investigated the development of silicone polyurethanes with improved biostability and mechanical properties for long-term biomedical applications such as pacemaker insulation or artificial heart valves ${ }^{33}$. They synthesized aromatic polyurethanes with mixed soft segments comprising hydroxyl-terminated PDMS and different polyethers, as well as aliphatic polycarbonate diols. Among all the synthesized polyurethanes, the combination of polyhexamethylene oxide (PHMO) and PDMS exhibits the best mechanical properties with respect to hard segment compatibility ${ }^{30}$. In subsequent studies, they further examined the effect of the PDMS-to-PHMO ratio and the incorporation of a disiloxane-based chain extender on the mechanical properties of silicone polyurethanes ${ }^{34,35,36}$. The results revealed that a macrodiol composition of $80 \mathrm{wt} \%$ PDMS and $20 \mathrm{wt} \%$ PHMO, in addition to a co-chain extender, such as 1,3-bis(4-hydroxybutyl)-tetramethyldisiloxane (BHTD), yields softer polyurethanes with good mechanical properties and thermoplastic processability. Furthermore, these silicone-polyurethanes exhibit an enhanced biostability compared to a commonly applied soft polyether urethane $\mathrm{e}^{37,38,39}$

The biocompatibility and stability of similar materials and their use for cardiovascular applications have also been reported ${ }^{40,41,42}$. Based on these results, silicone-based polyurea elastomers (or PSUs) with a disiloxane-based chain extender are thought to yield high flexibilities and softness, albeit with sufficient mechanical strength, to retain their shape after the application of repeated stress. For instance, Hermans et al. have constructed an experimental polyurethane-based dual-optic a-IOL prototype because the design, which was previously used for a fabrication using silicone, was extremely soft to handle the applied loads within enucleated pig eyes ${ }^{43}$.

This article describes the synthesis of a soft siloxane-based PSU, which is optimized in terms of mechanical and optical properties for applications as an accommodating IOL. As the mechanical properties of the PSU elastomers can be altered by the siloxane molecular weight, the same procedure can be applied to developing siloxane-based PSUs, which may find applications in coatings and skin dressings. In addition, this procedure can be used to prepare siloxane-based polyurethane or polyurethane-urea elastomers if carbinol-terminated PDMS is used. Depending on the type of diisocyanate (i.e., aliphatic or aromatic) used for synthesis, reaction conditions (including time, temperature, and perhaps the solvent composition) may have to be altered. For the application of aliphatic diisocyanates such as 4,4methylenebis(cyclohexylisocyanate) $\left(\mathrm{H}_{12} \mathrm{MDI}\right)$ or isophorone diisocyanate, the reaction has to be accelerated using an organotin catalyst, such as dibutyltin dilaurate or diacetoxytetrabutyl distannoxane. For example, the reaction between a hydroxypropyl-terminated PDMS and $\mathrm{H}_{12} \mathrm{MDI}$ proceeds in the presence of a catalyst. Furthermore, the reaction temperature needs to be increased to $50-60{ }^{\circ} \mathrm{C}$.For the application of an aromatic diisocyanate such as 4,4-methylenebis(phenylisocyanate) (MDI), the reaction temperature must be moderately but sufficiently increased as aromatic diisocyanates are typically more reactive toward nucleophilic groups than aliphatic diisocyanates are. The reaction of MDI with carbinol-terminated PDMS can be promoted by using the solvent mixtures of anhydrous tetrahydrofuran (THF) and dimethylformamide (DMF) or dimethylacetamide (DMAc) as tertiary amines exhibit some catalytic activity.

\section{Protocol}

CAUTION: Please consult all relevant material safety data sheets (MSDS) before use. Several chemicals used in the syntheses exhibit acute toxicity and strong irritation to the skin and eyes, as well as on inhalation. Please wear personal protective equipment (laboratory coats, safety glasses, hand gloves, full-length pants, and closed-toe shoes) and handle the chemicals, if possible, under a fume hood or in a well-ventilated place. Perform all syntheses under the fume hood. Tetramethylammonium hydroxide pentahydrate (TMAH): TMAH is a strong base, acutely toxic if swallowed, and upon skin contact, it causes severe chemical burns on skin and eyes. It is sensitive to air and is hygroscopic. Store it under refrigeration and nitrogen. Handle TMAH in a well-ventilated place because of its strong ammonia-like odor. APTMDS: APTMDS is sensitive to air and must be stored under nitrogen. It causes severe skin burns and eye damage. $\mathbf{H}_{12} \mathbf{M D I}$ : $\mathrm{H}_{12} \mathrm{MDI}$ is toxic upon inhalation and causes irritation to the skin and eyes. $\mathbf{D}_{4}$ : $\mathrm{D}_{4}$ may impair fertility. THF: THF is harmful, causes irritation on inhalation, and presumably is carcinogenic. Chloroform $\left(\mathrm{CHCl}_{3}\right): \mathrm{CHCl}_{3}$ is harmful on inhalation, presumably carcinogenic, can cause possible damage to fertility and an unborn child, and its vapors may cause drowsiness.

\section{Synthesis of the Catalyst and Amino-terminated Polysiloxane Macromonomers}

\section{Synthesis of the tetramethylammonium-3-aminopropyl-dimethylsilanolate catalyst}

NOTE: The catalyst was synthesized according to the method reported by Hoffman and Leir ${ }^{44}$

1. Degas APTMDS under vacuum before use and store it under nitrogen. Pipette approximately $10 \mathrm{~g}$ of APTMDS using a syringe. 
2. Add $8.13 \mathrm{~g}(33.0 \mathrm{mmol})$ of degassed APTMDS and $11.88 \mathrm{~g} \mathrm{(66.0} \mathrm{mmol})$ of TMAH into a $100 \mathrm{~mL}$ three-neck round-bottom flask. Add 20 $\mathrm{mL}$ of THF to dissolve APTMDS and to suspend TMAH, along with a large oval magnetic stir bar.

CAUTION: TMAH is a hygroscopic, corrosive, and toxic substance with a strong ammonia-like odor and should be stored tightly sealed in the refrigerator. Weigh TMAH immediately at a well-ventilated place; wear protective hand gloves and safety glasses while handling. APTMDS is air sensitive and causes skin burns and eye damage. Weigh APTMDS from a sealed bottle using a syringe; wear protective hand gloves and safety glasses while handling.

3. Equip the three-neck round-bottom flask with a reflux condenser and inlets and outlets for nitrogen and heat the reaction mixture to 80 ${ }^{\circ} \mathrm{C}$ using a glycerin or silicone oil heating bath. Stir the reaction mixture for $2 \mathrm{~h}$ under reflux and with a slight, continuous nitrogen flow. NOTE: The initial, slightly turbid suspension changes to a clear solution within $2 \mathrm{~h}$.

4. Remove the reflux condenser and distill off THF using a vacuum aspirator. Then, dry the slightly yellow crude product under a vacuum of 0.1 mbar for $5 \mathrm{~h}$ at $70^{\circ} \mathrm{C}$ using a Schlenk line.

NOTE: After this step, the crude product can be stored in the refrigerator at $10^{\circ} \mathrm{C}$ until the following day.

5. Resuspend the crude product in $50 \mathrm{~mL}$ of THF. If necessary, use a spatula to shred large agglomerates, and filter the suspension using a vacuum aspirator. Wash the precipitate at least $3 x$ with $20 \mathrm{~mL}$ THF portions until the product becomes a white powder-like solid.

6. Dry the product under a vacuum of $0.1 \mathrm{mbar}$ at room temperature for $3 \mathrm{~h}$. Then, store the catalyst in the refrigerator at $10^{\circ} \mathrm{C}$ under nitrogen until use.

2. Synthesis of $\alpha, \omega$-bis(3-aminopropyl)-polydimethylsiloxanes

NOTE: Synthesis of PDMS with a molecular weight of $\sim 15,500 \mathrm{~g} \cdot \mathrm{mol}^{-1}$.

1. Degas $\mathrm{D}_{4}$ and APTMDS under vacuum before use. Pipette approximately $1.5 \mathrm{~g}$ of APTMDS, using a syringe.

2. Add $19.5 \mathrm{~g}(65.7 \mathrm{mmol})$ of degassed $\mathrm{D}_{4}$ and $0.9 \mathrm{~g}(3.6 \mathrm{mmol})$ of APTMDS into a $100 \mathrm{~mL}$ three-neck round-bottom flask, which is equipped with a PTFE-coated centrifugal stirrer and a nitrogen inlet and outlet.

3. Add $\sim 26 \mathrm{mg}$ of the catalyst (from section 1.1) and stir the reaction mixture for $30 \mathrm{~min}$ at $80^{\circ} \mathrm{C}$ under a slight, continuous nitrogen flow. NOTE: A glycerin or silicone oil heating bath can be used.

4. Add $45.5 \mathrm{~g}(153.4 \mathrm{mmol})$ of $\mathrm{D}_{4}$ dropwise to the reaction mixture, using a dropping funnel (within $2-3 \mathrm{~h}$ ), and further stir at $80{ }^{\circ} \mathrm{C}$ for 24 $\mathrm{h}$ under a continuous nitrogen flow.

NOTE: The reaction can proceed overnight

5. Heat the reaction mixture to $150^{\circ} \mathrm{C}$ and stir it for $2 \mathrm{~h}$ to decompose the catalyst. Then, allow the PDMS to cool to room temperature.

6. Exchange the centrifugal stirrer with a large oval magnetic stir bar and seal the three-neck round-bottom flask with two stoppers. Use an adapter with a valve and slowly heat the PDMS to $150^{\circ} \mathrm{C}$ under a vacuum of 0.1 mbar to distill off the cyclic side products using a Schlenk line. Allow the PDMS to cool to room temperature. NOTE: Vacuum distillation typically occurs in $4-5 \mathrm{~h}$.

3. Synthesis of $\alpha, \omega$-bis(3-aminopropyl)-polydimethyl-methyl-phenylsiloxane NOTE: This section describes the synthesis procedure for a polysiloxane with a molecular weight of $\sim 15,500 \mathrm{~g} \cdot \mathrm{mol}^{-1}$ and $14 \mathrm{~mol} \% \mathrm{methyl}$ phenyl siloxane; this procedure is comparable to the PDMS synthesis, which is described in section 1.2.

1. Degas $D_{4}$ and APTMDS under vacuum before use. Pipette approximately $1.5 \mathrm{~g}$ of APTMDS using a syringe. Place $\mathrm{D}_{4}{ }^{\mathrm{Me}, \mathrm{Ph}}$ at $70{ }^{\circ} \mathrm{C}$ for $3-5 \mathrm{~h}$ in a vacuum chamber to completely melt and homogenize the product before use.

2. Add $4.54 \mathrm{~g}(15.3 \mathrm{mmol})$ of $\mathrm{D}_{4}, 14.96 \mathrm{~g}(27.5 \mathrm{mmol})$ of $\mathrm{D}_{4}{ }^{\mathrm{Me}, P h}$, and $0.9 \mathrm{~g}(3.6 \mathrm{mmol})$ of APTMDS into a $100 \mathrm{~mL}$ three-neck roundbottom flask, which is equipped with a PTFE-coated centrifugal stirrer and a nitrogen inlet and outlet.

3. Add $\sim 26 \mathrm{mg}$ of the catalyst (from section 1.1) and stir the reaction mixture at $80^{\circ} \mathrm{C}$ for 30 min under a continuous nitrogen flow.

4. Add $45.5 \mathrm{~g}(153.4 \mathrm{mmol})$ of $\mathrm{D}_{4}$ dropwise into the reaction mixture, using a dropping funnel (within $2-3 \mathrm{~h}$ ), and further stir at $80{ }^{\circ} \mathrm{C}$ for $24 \mathrm{~h}$ under a continuous nitrogen flow.

NOTE: The reaction can proceed overnight.

5. Proceed with the synthesis by following steps 1.2 .5 and 1.2.6.

\section{Molecular Weight Determination of Polysiloxane}

\section{Theoretical molecular weight of polysiloxane}

1. Calculate the theoretical molecular weight $\bar{M}_{n}$ of polysiloxane according to the following equation:

$\bar{M}_{n}=$ conversion $/ 100 \% \cdot \frac{m\left(\mathrm{D}_{4}\right)+m \text { (APTMDS) }}{n \text { (APTMDS) }}(1)$

Here, $\bar{M}_{n}$ is the number average molecular weight of polydimethylsiloxane, $m$ is the mass $(\mathrm{g})$ of the used monomers $\mathrm{D}_{4}$ and APTMDS, and $n$ is the amount of APTMDS in moles.

2. Molecular weight determination of polysiloxane by ${ }^{1} \mathrm{H}-\mathrm{NMR}$ spectroscopy

1. Dissolve $10-20 \mathrm{mg}$ of polysiloxane in $0.5 \mathrm{~mL}$ of $\mathrm{CDCl}_{3}$, record its NMR spectrum, and calibrate chemical shifts [ס] to the solvent signal at $7.26 \mathrm{ppm}$.

2. Calculate the molecular weight $\bar{M}_{n}$ of polysiloxane from the integral values according to the following equation.

$M_{n}=\frac{\text { Integral value }(\approx 0.07 \mathrm{ppm}) / 6 \mathrm{H}}{\text { Integral values }(\approx 2.69+0.56 \mathrm{ppm}) / 8 \mathrm{H}} \cdot 74.155+100\left(\mathrm{~g} \cdot \mathrm{mol}^{-1}\right)(2)$

3. Molecular weight determination of polysiloxane by titration

1. Add $1.5-2 \mathrm{~g}$ of polysiloxane into a $250 \mathrm{~mL}$ conical flask and dissolve it in $50 \mathrm{~mL}$ of $\mathrm{THF}$ under continuous stirring using a magnetic stir bar. 
2. Titrate amino groups with $0.1 \mathrm{M} \mathrm{HCl}$ using bromophenol blue until a color change from blue to yellow is observed. Repeat the titration with three samples to calculate the number average molecular weight.

\section{Synthesis of Polysiloxane-urea Elastomers}

NOTE: This section describes the synthesis procedure for a PDMS-based urea elastomer of $10 \mathrm{w} \%$ hard-segment content (HS\%) (PDMS: $\left.15,500 \mathrm{~g} \cdot \mathrm{mol}^{-1}\right)$.

$\mathrm{HS} \%=\left(\frac{\mathrm{H}_{12} \text { MDI }(\mathrm{g})+\text { APTMDS }(\mathrm{g})}{\mathrm{H}_{12} \text { MDI }(\mathrm{g})+\text { APTMDS }(\mathrm{g})+\text { polysiloxane }(\mathrm{g})}\right) \cdot 100 \%(3)$

1. Add $2.939 \mathrm{~g}(11.2 \mathrm{mmol})$ of $\mathrm{H}_{12} \mathrm{MDI}$ into a $250 \mathrm{~mL}$ four-neck round-bottom reaction flask, which is equipped with a PTFE-coated centrifugal stirrer, dropping funnel, and nitrogen inlet and outlet, and dissolve it in $20 \mathrm{~mL}$ of THF.

CAUTION: $\mathrm{H}_{12} \mathrm{MDI}$ is a low volatile diisocyanate and causes irritation to the skin and eyes. Wear protective hand gloves and safety glasses. NOTE: Alternatively, dissolve $\mathrm{H}_{12} \mathrm{MDI}$ in THF in a $50 \mathrm{~mL}$ beaker and add the solution through a funnel or a tulip glass into the reaction flask.

Then, rinse the beaker and funnel with $10 \mathrm{~mL}$ of THF.

1. Dissolve $45.0 \mathrm{~g} \mathrm{(2.9} \mathrm{mmol)} \mathrm{of} \mathrm{degassed} \mathrm{PDMS} \mathrm{in} 100 \mathrm{~mL}$ of THF; add this solution dropwise into the $\mathrm{H}_{12} \mathrm{MDI}$ solution using a dropping funnel under continuous stirring and a nitrogen flow at room temperature. Rinse the beaker and dropping funnel with $50 \mathrm{~mL}$ of THF and add this solution to the reaction mixture.

2. Control the formation of the prepolymer via FTIR spectroscopy.

NOTE: The reaction progress can be monitored in two ways: using inline or offline ATR-FTIR spectroscopy.

1. For inline ATR-FTIR spectroscopy, insert an inline ATR-FTIR probe, which is connected to the spectrometer, into the central joint at the start of the reaction. Use a large oval magnetic stir bar instead of a PTFE-coated stirrer. Start recording the spectra of the $\mathrm{H}_{12} \mathrm{MDI}$ solution and select the NCO absorption peak at $2266 \mathrm{~cm}^{-1}$ to follow the conversion of isocyanate groups.

2. For offline ATR-FTIR spectroscopy, take samples of the reaction mixture using a Pasteur pipette and add a few drops on the ATR crystal. Evaporate the solvent under a nitrogen flow until a thin film remains on the ATR crystal surface. Record spectra at different reaction stages (after the complete addition of PDMS and after the addition of each portion of APTMDS).

3. Add portions of the stoichiometric amount of the chain extender APTMDS to the prepolymer solution.

NOTE: The addition of the chain extender can proceed in two ways (see steps 3.1.3.1 and 3.1.3.2).

1. Dissolve the weighed amount of the chain extender in $5-10 \mathrm{~mL}$ of THF and add the solution dropwise to the reaction mixture using a Pasteur pipette or using a dropping funnel, followed by rinsing again with $3 \mathrm{~mL}$ of THF.

2. Add portions of the chain extender into a syringe and add the chain extender dropwise to the reaction mixture. In this case, sea the fourth joint using a rubber septum stopper.

1. Add $1.65 \mathrm{~g}(6.6 \mathrm{mmol})$ of APTMDS, corresponding to $80 \%$ of the calculated amount of APTMDS, to the prepolymer. Then, control the reaction progress via FTIR spectroscopy.

2. Then, add $0.21 \mathrm{~g}(0.8 \mathrm{mmol})$ of APTMDS (in total, $90 \%$ of the calculated amount) to the reaction mixture and control the reaction progress by FTIR

3. Add $0.1 \mathrm{~g}(0.4 \mathrm{mmol})$ of APTMDS (in total, $95 \%)$ to the reaction mixture and control the reaction progress using FTIR.

4. Finally, add the last portion of the chain extender $(0.102 \mathrm{~g}, 0.41 \mathrm{mmol})$ to the reaction mixture and check the disappearance of the NCO absorption band in the FTIR spectrum.

NOTE: After the addition of the first portion of the chain extender, an increase in viscosity is noted.

4. Pour the PSU solution into a PTFE-foil-covered glass Petri dish and evaporate the solvent overnight under the fume hood.

Furthermore, dry the PSU in a vacuum chamber at $80^{\circ} \mathrm{C}$ for $12 \mathrm{~h}$.

\section{Mechanical Testing Procedure}

1. Preparation of polysiloxane-urea elastomer films

1. Dissolve $7-8 \mathrm{~g}$ of small PSU pieces in $200-250 \mathrm{~mL}$ of $\mathrm{CHCl}_{3}$ in a $300 \mathrm{~mL}$ conical flask, loosely seal the flask using a glass stopper, and stir the mixture using a magnetic stir bar for at least $24 \mathrm{~h}$. If necessary, add additional portions of solvent. CAUTION: Chloroform is presumably carcinogenic. Vapors may cause drowsiness upon inhalation. Handle chloroform at a wellventilated place.

2. Add the homogeneous solution into a glass Petri dish and cover it with perforated aluminum foil. Allow the solvent to evaporate slowly either by placing the Petri dish in a well-ventilated place or in a fume hood with the sash window open.

NOTE: When placing the Petri dish in the fume hood, decrease the airflow if possible. Extremely rapid evaporation of the solvent leads to inhomogeneity and the formation of opaque stains within the transparent films.

3. Dry the film at $80^{\circ} \mathrm{C}$ in a vacuum chamber for $12 \mathrm{~h}$.

4. Carefully remove the film from the glass surface using a small thin spatula and store the PSU film within a transparent envelope upon subsequent use for mechanical characterization.

2. Stress-strain tests on polysiloxane-urea elastomer films

1. Prepare die-cut dog-bone-shaped specimens from the PSU films according to Keiper ${ }^{45}$ (type S2). Place the PSU film, which is covered by envelope foils, under a punching knife unit with a shape as shown in Figure 4. Push the lever down to punch out the test specimen and store it for at least $72 \mathrm{~h}$ at ambient temperature $\left(23 \pm 2{ }^{\circ} \mathrm{C}\right)$. 
2. Switch on the tensile testing machine and computer. Start the software by clicking on the icon. Select the method as tensile test and check if the correct load cell $(100 \mathrm{~N})$ is installed in the testing machine.

3. Select the method assistant and check if all test settings are correct. Go to pre-test and check if the following settings are activated: the original sample length $\left(L_{0}\right)$ at $20 \mathrm{~mm}$, the preload at $0.1 \mathrm{MPa}$, and the velocity until preload is reached at $5 \mathrm{~mm} / \mathrm{min}$.

4. Go to test parameter and check if the following settings are activated: the velocity for the determination of Young's modulus at $1 \mathrm{~mm} /$ $\mathrm{min}$, the velocity until sample break at $25 \mathrm{~mm} / \mathrm{min}$, the detection of sample break at $80 \% \mathrm{~F}_{\text {max }}$, the determination of Young's modulus at Regression, the beginning of Young's modulus determination at $2 \%$ strain, and the end of Young's modulus determination at $6 \%$ strain. Leave the method assistant and switch to the main window of the software.

5. Push the power on button on the testing machine and click the button go to starting position in the main window of the software.

6. Remove the protection foils and inspect the sample under a cross-polarizer to exclude any internal stress. Measure the sample thickness and sample width using a caliber. Then, insert the values for sample thickness and width into the corresponding fields in the main window of the software.

7. Fix the test specimen between the upper clamping jaws of the testing machine. Click the button zero force in the main window of the software. Fix the bottom end of the test specimen between the bottom clamping jaws of the testing machine.

NOTE: If the surfaces of the clamping jaws are slippery, position the ends of the specimen between fine-grain emery paper to prevent the specimen from slipping during measurement.

8. Click the start measurement button to start the tensile test.

9. After completing the measurement, proceed with steps 4.2.6 and 4.2.7. After fixing the test specimen between the upper clamping jaws and selecting zero force, select the button go to starting position on the main window of the software. Then, fix the bottom end of the test specimen between the bottom clamping jaws and click start measurement again.

10. Repeat steps 4.2.6 - 4.2.8 for one PSU sample at least an additional $3 x$ for the statistical evaluation of Young's modulus, tensile strength, and elongation at break.

\section{Hysteresis tests on PSU elastomer films}

1. Switch on the tensile testing machine and computer. Start the software by clicking on the icon. Select the method as cyclic tensile test and check the installation of the correct load cell $(100 \mathrm{~N})$ in the testing machine.

2. Select the method assistant and check if all test settings are correct. Go to pre-test and check whether the following settings are activated: the original sample length $\left(L_{0}\right)$ at $20 \mathrm{~mm}$, the preload at $0.05 \mathrm{MPa}$, and the velocity until preload is reached at $5 \mathrm{~mm} / \mathrm{min}$

3. Go to the test parameter and check the activation of the following settings: the number of cycles at 10 , the setpoint loading at $100 \%$ strain, the setpoint unloading at $0 \%$ strain, and the velocity at $25 \mathrm{~mm} / \mathrm{min}$. Leave the method assistant and switch to the main window of the software.

4. Proceed with steps $4.2 .5-4.2 .8$.

5. Repeat the hysteresis measurements with two specimens for statistical evaluation. Calculate the mechanical hysteresis for each cycle according to the following equation.

$\%$ Hysteresis $=\frac{\text { area under the loading curve } \text { - area under the recovery curve }}{\text { area under the loading curve }} \cdot 100 \%(4)$

\section{Cultivation Procedure for HaCaT Cells}

1. Warm a cryotube with HaCaT cells and Dulbecco's modified Eagle's medium (DMEM) in a $37^{\circ} \mathrm{C}$ water bath. Under the microbiological safety workbench, rapidly transfer the cell suspension to a $10 \mathrm{~mL}$ conical centrifuge tube, which is filled with warm DMEM.

1. Subject the cell suspension to centrifugation for $6 \mathrm{~min}$ at $845 \mathrm{xg}$. Discard a majority of the supernatant using a disposable glass Pasteur pipette, which is attached to a vacuum pump, and resuspend the cell pellet in the remaining liquid by gently pipetting the cell agglomerates up and down using an Eppendorf pipette.

2. Transfer the resuspended cells to a $25 \mathrm{~cm}^{2}$ cell culture flask and add $9 \mathrm{~mL}$ of DMEM, which is supplemented with $10 \%$ FBS. Incubate the cells at $37 \pm 1{ }^{\circ} \mathrm{C}$ and $5 \% \mathrm{CO}_{2}$ in an incubator cabinet. Control the cell proliferation daily using an inverted microscope. Change the DMEM each third day until the cells become subconfluent.

3. Perform a cell passage under the safety workbench by removing the DMEM using a disposable glass Pasteur pipette. Add $10 \mathrm{~mL}$ of PBS buffer to wash the cell layer. Remove the PBS buffer using a disposable glass Pasteur pipette again.

4. Add $1 \mathrm{~mL}$ of a trypsin/EDTA solution to the $25 \mathrm{~cm}^{2}$ cell culture flask to detach the cells and incubate them in the $\mathrm{CO}_{2}$ incubator cabinet. Check if the cells are present in the suspension, using an inverted microscope.

5. Add $3 \mathrm{~mL}$ of DMEM to the cell culture flask to inactivate the trypsin. Transfer the cell suspension to a centrifuge tube and subject the cells to centrifugation for 6 min at $845 \times$ g. Remove a majority of the supernatant, using a glass Pasteur pipette. Resuspend the cells in the remaining DMEM and add $10 \mathrm{~mL}$ of fresh warm DMEM, which is supplemented with $10 \% \mathrm{FBS}$.

6. Transfer $5 \mathrm{~mL}$ of the cell suspension into each of the $75 \mathrm{~cm}^{2}$ cell culture flasks and add $15 \mathrm{~mL}$ of fresh warm DMEM, supplemented with $10 \%$ FBS. Cultivate $\mathrm{HaCaT}$ cells at $37 \pm 1{ }^{\circ} \mathrm{C}$ and $5 \% \mathrm{CO}_{2}$ in the $\mathrm{CO}_{2}$ incubator cabinet until the cells become subconfluent.

7. Repeat the cell passage according to steps $5.1 .3-5.1 .6$ but this time, use $2 \mathrm{~mL}$ of a trypsin/EDTA solution and $6 \mathrm{~mL}$ of DMEM to inactivate the trypsin.

\section{Procedure for an MTS Cell Viability Assay Using HaCaT Cells}

NOTE: In vitro cytotoxicity tests were performed according to Wenzelewski ${ }^{46}$, using cell medium extracts. PSU samples and biomedical-grade polyurethane samples were sterilized using ethylene oxide.

1. Culture $\mathrm{HaCaT}$ cells at $37 \pm 1^{\circ} \mathrm{C}$ and $5 \% \mathrm{CO}_{2}$ in DMEM, which is supplemented with $10 \% \mathrm{FBS}$ in a $75 \mathrm{~cm}^{2}$ cell culture flask. Use the cells for in vitro cytotoxicity tests, at least after the fourth passage. 
1. Add sterile samples of PSU and a reference material $(0.7 \mathrm{~g})$ into $50 \mathrm{~mL}$ conical centrifuge tubes and extract the samples with DMEM, without FBS, for $72 \pm 2 \mathrm{~h}$ at $37^{\circ} \mathrm{C}$ and $5 \% \mathrm{CO}_{2}$ at an extraction ratio of $0.1 \mathrm{~g} / \mathrm{mL}$. Use three extracts for each PSU sample. Prepare blind samples by filling DMEM, without FBS, into $50 \mathrm{~mL}$ conical centrifuge tubes and perform the same extraction.

2. On day 2 of the extraction procedure, perform cell detachment according to steps $5.1 .3-5.1 .5$ with $2 \mathrm{~mL}$ of trypsin/EDTA and $6 \mathrm{~mL}$ of DMEM. Take a $100 \mu \mathrm{L}$ aliquot of the cell suspension and add $100 \mu \mathrm{L}$ of DMEM. From this diluted suspension, take $20 \mu \mathrm{L}$ of aliquot and add $10 \mu \mathrm{L}$ of a $0.5 \%$ trypan blue solution to stain dead cells.

3. Incubate the cells for 2 min. Fill the hemocytometer using a micropipette and immediately count the cells within the four chambers. Calculate the numbers of viable and nonviable cells to evaluate cell viability in percentages.

NOTE: Alternatively, the cells can be counted using a cell counting system.

4. Seed HaCaT cells (fourth passage) at a concentration of $20 \times 10^{3}$ cells/well in $200 \mu \mathrm{L}$ of DMEM into 96-well microplates and incubate the cells for $24 \mathrm{~h}$ at $37^{\circ} \mathrm{C}$ and $5 \% \mathrm{CO}_{2}$.

5. On day 3, after the extraction, add $10 \%$ FBS to each of the extract and blind samples and warm the samples up to $37^{\circ} \mathrm{C}$ using a water bath. Remove the DMEM from each seeded well and replace the medium by the extracts, blind samples, and the corresponding positive and negative controls. For each PSU extract (use three extracts for each PSU sample), pipette $200 \mu \mathrm{L}$ of the extract into six wells.

6. Pipette $200 \mu \mathrm{L}$ of the blind sample (DMEM $+10 \%$ FBS) into six wells. Pipette $200 \mu \mathrm{L}$ of fresh DMEM, supplemented with $10 \%$ FBS (negative control), into six wells. Pipette $200 \mu \mathrm{L}$ of the positive control (DMEM $+10 \% \mathrm{FBS}+1 \% \mathrm{SDS}$ ) into six wells. Incubate the cells with the extracts and controls for $24 \mathrm{~h}$ at $37^{\circ} \mathrm{C}$ and $5 \% \mathrm{CO}_{2}$.

NOTE: For the preparation of a positive control, prepare a $20 \%$ SDS solution in water and dilute it with DMEM at 1:2. Then, further dilute it with DMEM to prepare a $1 \%$ SDS solution.

7. On day 4 , shortly before the end of the incubation time, prepare a stock solution of MTS and DMEM without FBS (for each well, use 20 $\mu \mathrm{L}$ of MTS solution $+100 \mu \mathrm{L}$ of DMEM). After the incubation time, remove the extracts, blind solutions, and controls, and pipette $120 \mu \mathrm{L}$ of the MTS stock solution into each well, as well as into six wells without cells to determine the background. Incubate the cells for $4 \mathrm{~h}$ at $37^{\circ} \mathrm{C}$ and $5 \% \mathrm{CO}_{2}$.

8. On day 4 after the incubation of the MTS solution, measure the absorbance of each well at $492 \mathrm{~nm}$, using a microplate reader. Subtract the measured absorbance of the background from that of the seeded wells. Assume that the measured absorbance values from the positive control represent $0 \%$ proliferation and set those absorbance values to 0 . Assume that the measured absorbance values from the negative control represent $100 \%$ proliferation and set those values to 100 .

9. Calculate the cell proliferation from the absorbance values as a percentage of the absorbance values from the negative control (100\% proliferation) and positive control ( $0 \%$ proliferation). Evaluate the sample extracts that exhibit cell proliferation of up to $81 \%$ as not cytotoxic.

NOTE: According to the supplier's information ${ }^{47}$, measure the absorbance later. Pipette $25 \mu \mathrm{L}$ of a $10 \%$ SDS solution into each well to stop the reaction and store the microplate for up to $18 \mathrm{~h}$ protected from light at room temperature in a humidified chamber.

\section{Representative Results}

The ring-chain equilibration of $\mathrm{D}_{4}$ and $\mathrm{D}_{4}{ }^{\mathrm{Me}, \mathrm{Ph}}$ with the endblocker APTMDS yielded aminopropyl-terminated polydimethylsiloxanes and polydimethyl-methyl-phenyl-siloxane-copolymers, respectively, which were synthesized with molecular weights between 3,000 and 33,000 $\mathrm{g} \cdot \mathrm{mol}^{-1}$ by adjusting the monomer ratio between $\mathrm{D}_{4}$ and APTMDS (Figure 6). Molecular weights $\bar{M}_{n}$ of the prepared PDMS, which were determined from ${ }^{1} \mathrm{H}-\mathrm{NMR}$ spectra (Figure 5), were similar to the values obtained from titration. These values were in agreement with the calculated theoretical molecular weights of up to $15,000 \mathrm{~g} \cdot \mathrm{mol}^{-1}$. During the preparation of PDMS with higher molecular weights, the obtained molecular weights were slightly greater than those presumed by theoretical calculation. The copolymerization of the cyclic siloxane with pendant phenyl groups $\mathrm{D}_{4}{ }^{\mathrm{Me}}, \mathrm{Ph}$ was deemed successful for slightly increasing the refractive index of polysiloxanes. The refractive index (determined using the Abbe refractometer at $37^{\circ} \mathrm{C}$ ) increased from 1.401 (unmodified PDMS) to 1.4356 (14 mol\% methyl-phenyl-siloxane) (Figure 7).PSU elastomers were synthesized in two steps using the prepared aminopropyl-terminated PDMS, aliphatic diisocyanate $\mathrm{H}_{12} \mathrm{MDI}$, and APTMDS, using THF as the solvent. This method permitted the construction of high-molecular-weight PSUs with a segmented structure of soft segments (PDMS) and hard segments (diisocyanate + urea). Inline FTIR spectroscopy confirmed the extremely rapid reaction of the isocyanate groups with the amino groups from the PDMS and the chain extender APTMDS (Figure 3 and Figure 8). Unlike the preparation of the polyurethane elastomers, which takes several hours, the preparation of the PSU elastomers was convenient. The transparency and mechanical properties of PSU elastomers were dependent on the PDMS molecular weight. Transparent PSU elastomer films exhibited a transmittance of $>90 \%$ up to a PDMS molecular weight of $18,000 \mathrm{~g} \cdot \mathrm{mol}^{-1}$. At higher PDMS molecular weights, the PSU films became increasingly opaque (Figure 9). With the increase in the PDMS molecular weight, soft PSU elastomers could be prepared. The Young's modulus of PSU elastomers decreased from $\sim 5.5$ $\mathrm{MPa}$ (with a PDMS molecular weight of $3,000 \mathrm{~g} \cdot \mathrm{mol}^{-1}$ ) to $0.6 \mathrm{MPa}$ (with a PDMS molecular weight of $\geq 26,000 \mathrm{~g} \cdot \mathrm{mol}^{-1}$ ) $\left(\mathrm{Figure}^{10}\right.$ ). Furthermore, mechanical hysteresis, which was used to evaluate the mechanical stability under repeated applied stress, was reduced for the PSU elastomers when they were prepared from high-molecular-weight PDMS. The hysteresis values for the first cycle at a $100 \%$ strain decreased from $54 \%$ (with a PDMS molecular weight of $3,000 \mathrm{~g} \cdot \mathrm{mol}^{-1}$ ) to $6 \%$ (with a PDMS molecular weight of $33,000 \mathrm{~g} \cdot \mathrm{mol}^{-1}$ ) (Figure 11). The applied synthesis method permitted the preparation of PSU elastomers that do not release cytotoxic residuals as examples shown in cell viability tests performed with extracts of some selected PSU elastomers on HaCaT cells (Figure 12). 


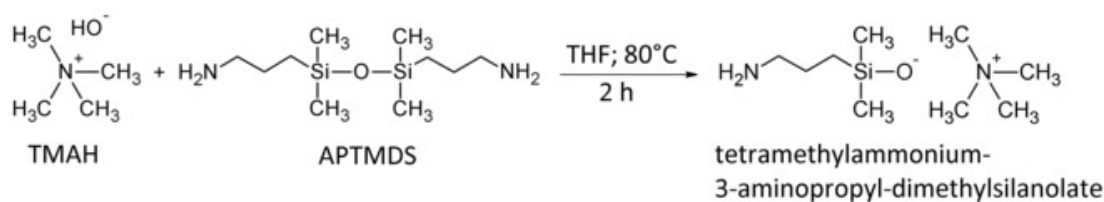

Figure 1: Synthesis of the tetramethylammonium-3-aminopropyl-dimethylsilanolate catalyst.

Tetramethylammonium hydroxide pentahydrate (TMAH) and 1,3-Bis(3-aminopropyl)-tetramethyldisiloxane (APTMDS) were reacted $2 \mathrm{~h}$ in THF at $80^{\circ} \mathrm{C}$. The catalyst tetramethylammonium-3-aminopropyl-dimethylsilanolate is received as a white solid after washing the crude product with THF. Please click here to view a larger version of this figure.

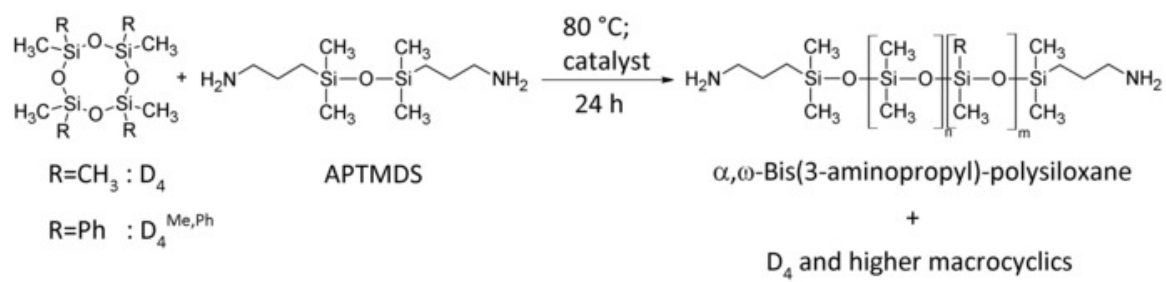

Figure 2: Synthesis route for aminopropyl-terminated polydimethylsiloxanes (PDMS) and polydimethyl-methyl-phenylsiloxane-copolymers. Cyclic monomers $\mathrm{D}_{4} / \mathrm{D}_{4}{ }^{\mathrm{Me}, \mathrm{Ph}}$ are equilibrated using a disiloxane endblocker APTMDS at $80^{\circ} \mathrm{C}$ for $24 \mathrm{~h}$ using the tetramethylammonium-3-aminopropyl-dimethylsilanolate catalyst. This figure has been modified from Riehle et al. ${ }^{48}$. Please click here to view a larger version of this figure.

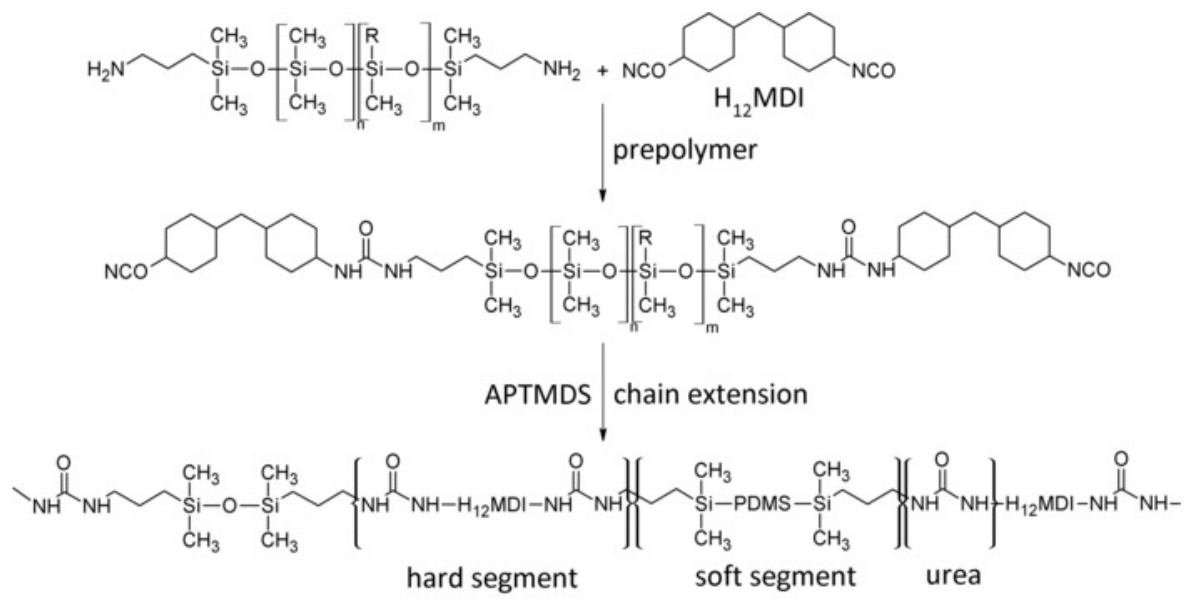

Figure 3: Two-step synthesis of segmented polysiloxane-based urea elastomers (PSU). In the first step, a prepolymer containing active isocyanate groups is formed after the reaction of $\mathrm{H}_{12} \mathrm{MDI}$ with aminopropyl-terminated polysiloxane $\left(\mathrm{R}=\mathrm{CH}_{3}\right.$ : $\mathrm{PDMS} ; \mathrm{R}=\mathrm{Ph}$; copolymer). In the second step, the polymer molecular weight is increased via the reaction of the remaining active isocyanate groups with the chain extender APTMDS. The resulting elastomer is a segmented polymer comprising urea hard segments and silicone soft segments. This figure has been modified from Riehle et al. ${ }^{48}$. Please click here to view a larger version of this figure.

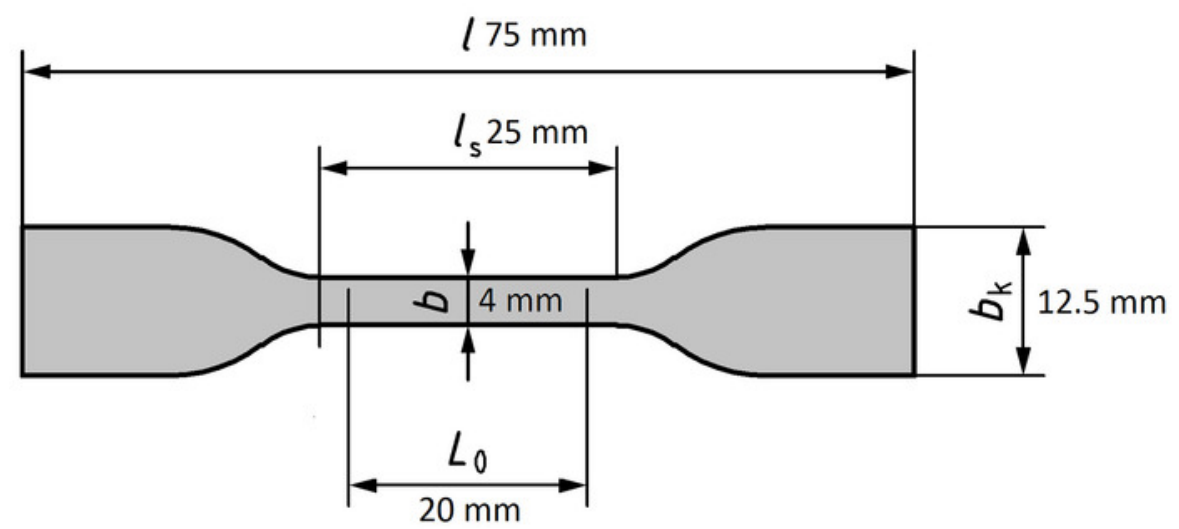

Figure 4: Specification of the dog-bone-shaped test specimen for stress-strain tests. This figure has been modified from Keiper ${ }^{45}$. Please click here to view a larger version of this figure. 


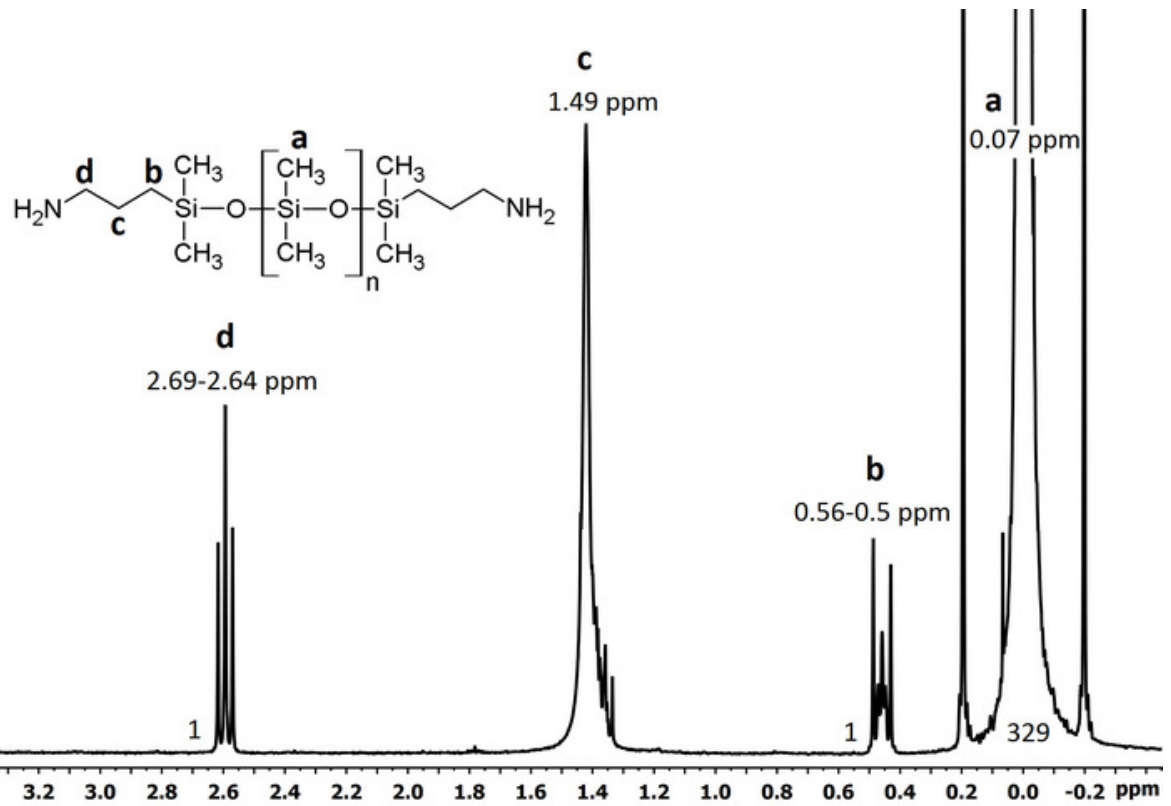

Figure 5: ${ }^{1} \mathrm{H}-\mathrm{NMR}$ spectrum of aminopropyl-terminated polydimethylsiloxane. For the molecular weight calculation, integral values of the methylene protons $d(\delta 2.69 \mathrm{ppm})$ and $\mathrm{b}(\delta 0.56 \mathrm{ppm})$ and methyl protons a $(\delta \sim 0.07 \mathrm{ppm})$ were utilized. The peak $\mathrm{c}(\delta \sim 1.5 \mathrm{ppm})$ is overlaid by the $\mathrm{HDO}$ peak ${ }^{49}$, corresponding to the proton exchange of water traces with solvent $\mathrm{CDCl}_{3}$; hence, this peak is not used to calculate the molecular weight. The PDMS molecular weight in this spectrum is $\sim 16,365 \mathrm{~g} \cdot \mathrm{mol}^{-1}$. Please click here to view a larger version of this figure.

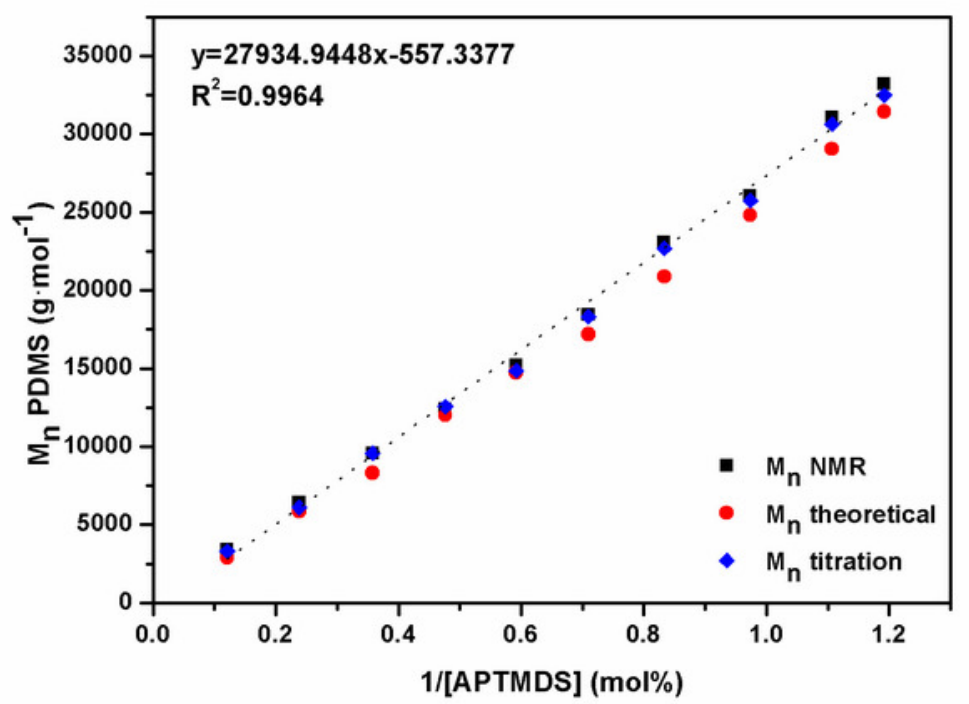

Figure 6: Linear correlation between the molecular weight $\bar{M}_{n}$ of aminopropyl-terminated polydimethylsiloxanes and endblocker concentration. $\bar{M}_{n}$ values were determined via ${ }^{1} \mathrm{H}-\mathrm{NMR}$ spectroscopy, the titration of amino end groups, and the theoretical calculation according to equation (1). This figure is reprinted with permission from Riehle et al. ${ }^{48}$. Please click here to view a larger version of this figure. 


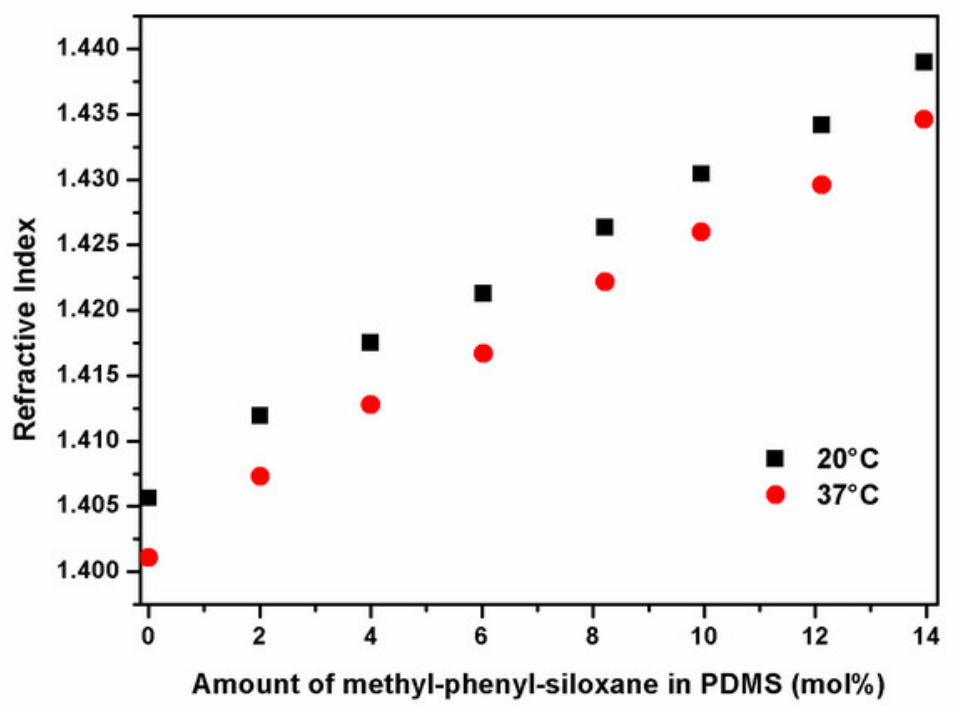

Figure 7: Refractive indices of aminopropyl-terminated polydimethyl-methyl-phenyl-siloxane-copolymers. Refractive indices (RI) of polydimethyl-methyl-phenyl-siloxane-copolymers were determined at $20^{\circ} \mathrm{C}$ (black squares) and $37^{\circ} \mathrm{C}$ (red circles) using an Abbe refractometer. The RI values linearly increased with the amount of the incorporated methyl-phenyl-siloxane units. RI values at 0 mol\% represent those from unmodified PDMS with a molecular weight comparable to the polydimethyl-methyl-phenyl-siloxane-copolymers. An optimal RI of 1.4346 (37 ${ }^{\circ} \mathrm{C}$ ) was obtained for a copolymer with $14 \mathrm{~mol} \%$ of methyl-phenyl-siloxane. This figure has been reprinted with permission from Riehle et al. ${ }^{48}$. Please click here to view a larger version of this figure.

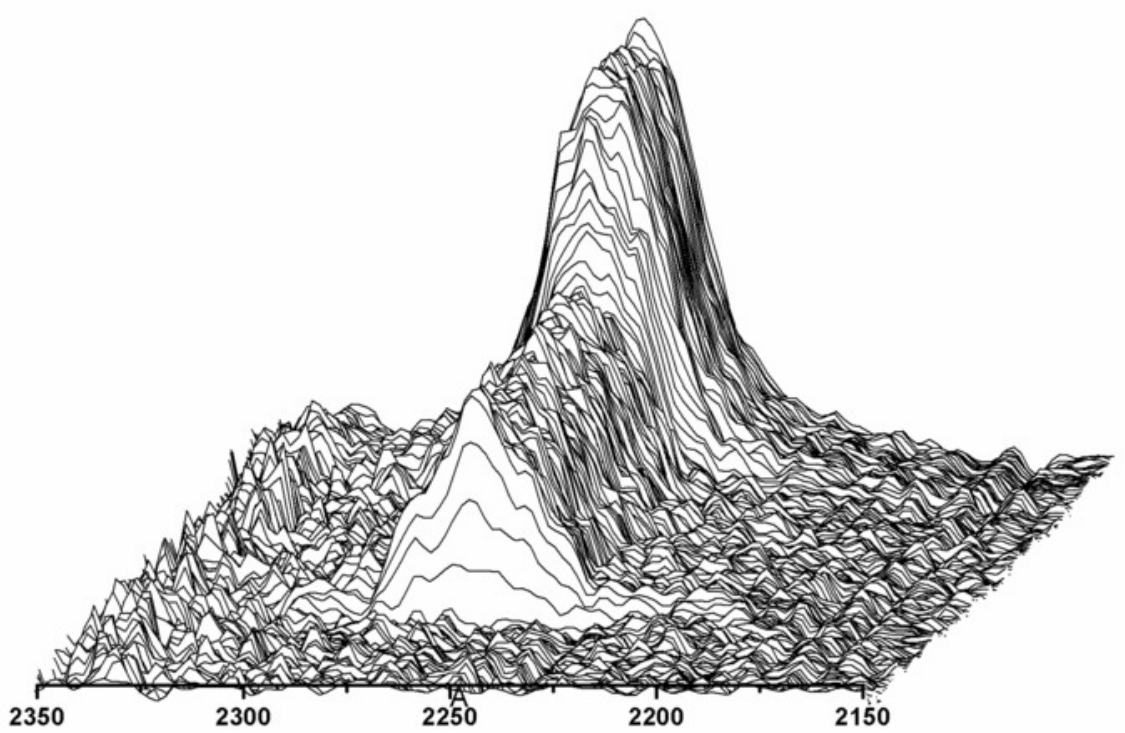

Figure 8: Isocyanate conversion during the synthesis of polydimethylsiloxane-urea (PSU). This figure shows a time-dependent plot of the NCO absorption band at $2,266 \mathrm{~cm}^{1}$ followed by inline FTIR-ATR spectroscopy during the synthesis of PSU.After the addition of aminopropylterminated polydimethylsiloxane, the height of the NCO band decreased, indicative of the formation of NCO-terminated prepolymer chains. After the addition of the chain extender APTMDS, the NCO band completely disappeared from the IR spectra. This figure has been reprinted with permission from Riehle et al. ${ }^{50}$. Please click here to view a larger version of this figure. 


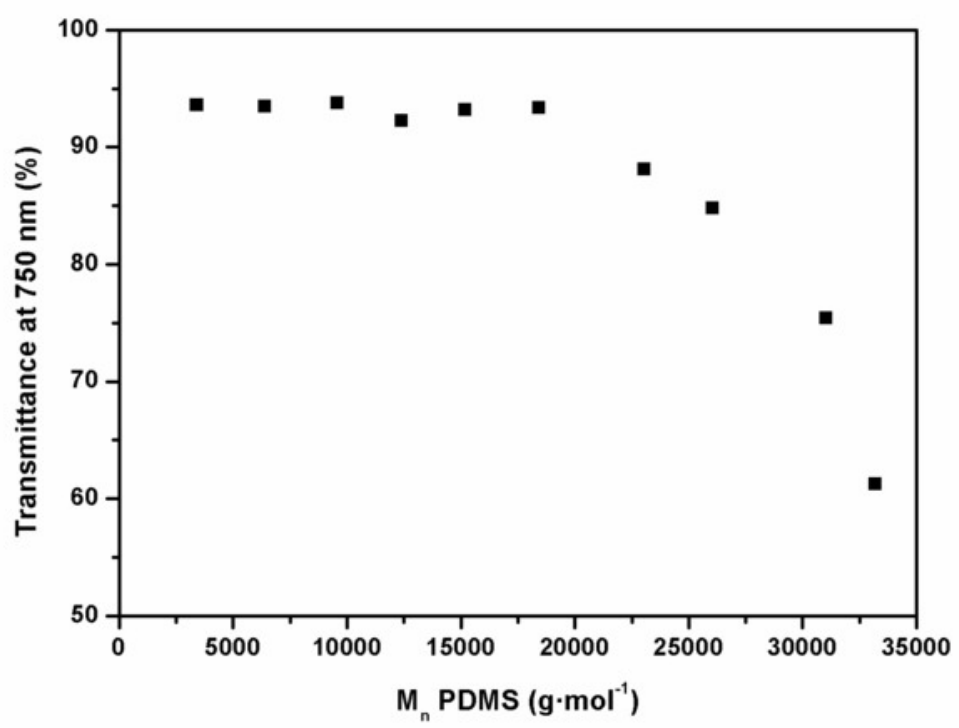

Figure 9: Dependence of the transmittance of PSU elastomer films at $750 \mathrm{~nm}$ and the molecular weight of polydimethylsiloxane. The transmittance of the PSU films was determined by UV-Vis spectroscopy. The transmittance of PSUs at $750 \mathrm{~nm}$ (the upper edge of the visible spectrum) was $>90 \%$ if PSUs were synthesized using PDMS with molecular weights ranging between 3,000 and $18,000 \mathrm{~g} \cdot \mathrm{mol}^{-1}$. With an increasing molecular weight of PDMS, the opacity of films increased. This figure has been reprinted with permission from Riehle et al. ${ }^{48}$. Please click here to view a larger version of this figure.

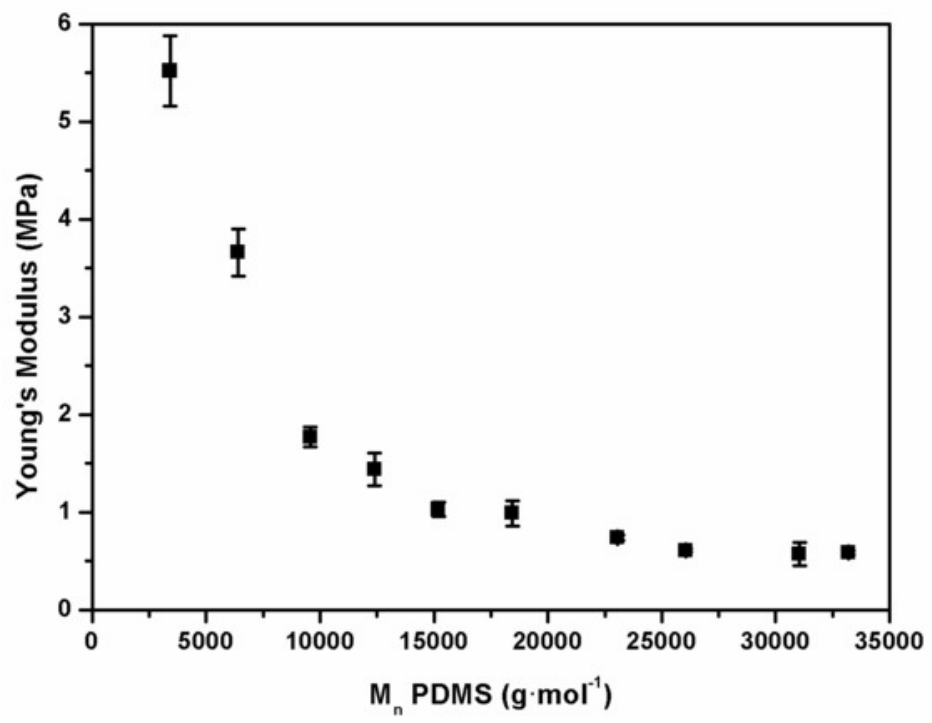

Figure 10: Young's modulus of PSU elastomers as a function of the molecular weight of polydimethylsiloxane. Young's moduli (YM) were determined from stress-strain measurements of the PSU films. The values are expressed as a mean value obtained from five repeated measurements. The error bars represent the standard deviation. The highest decrease of YM was observed for PSUs synthesized from PDMS ranging from 3,000 to $9,000 \mathrm{~g} \cdot \mathrm{mol}^{-1}$. At PDMS molecular weights between 12,000 and $18,000 \mathrm{~g} \cdot \mathrm{mol}^{-1}$, YM values were between $1.5 \mathrm{MPa}$ and 1.0 $\mathrm{MPa}$. At molecular weights greater than $26,000 \mathrm{~g} \cdot \mathrm{mol}^{-1}$, YM values were $\sim 0.6 \mathrm{MPa}$. This figure has been reprinted with permission from Riehle et $\mathrm{al}^{48}$. Please click here to view a larger version of this figure. 


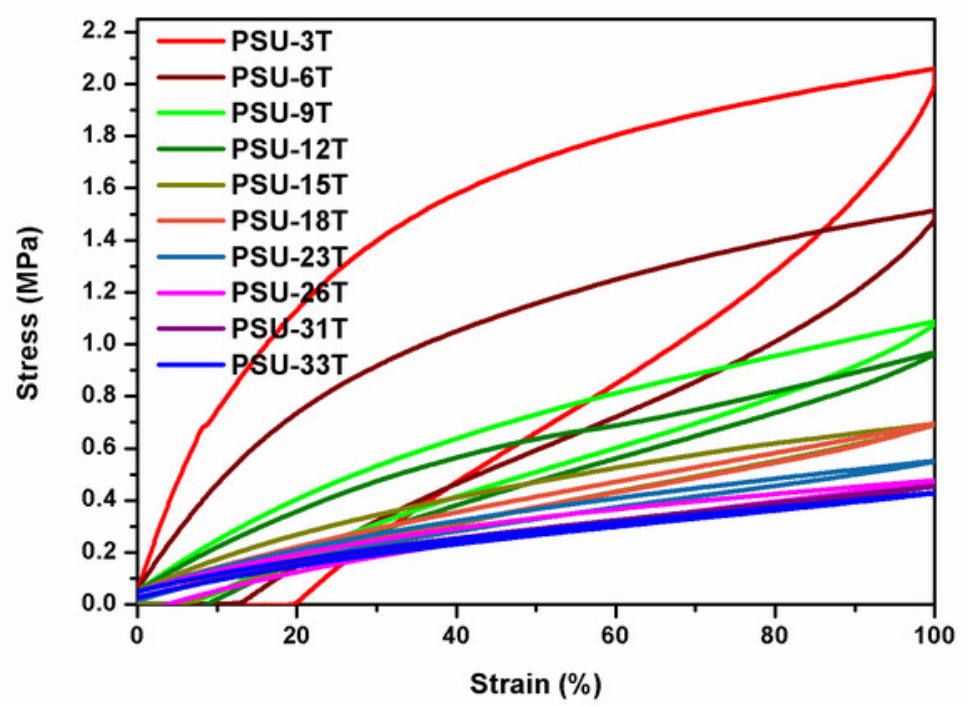

Figure 11: $100 \%$ hysteresis curves of PSU elastomers. The first-cycle hysteresis curves of the PSU elastomers at $100 \%$ elongation are shown. The polymer notation refers to the PDMS molecular weight (e.g., PSU-3T is a polyurea elastomer prepared from PDMS with a molecular weight of $\left.3,000 \mathrm{~g} \cdot \mathrm{mol}^{-1}\right)$. The highest mechanical hysteresis $(43 \%-54 \%)$ was observed in PSU elastomers synthesized from low-molecularweight PDMS, as indicated by the pronounced hysteresis curves. Hysteresis decreased with the increase in the PDMS molecular weight from $14 \%\left(15,000 \mathrm{~g} \cdot \mathrm{mol}^{-1}\right)$ to $6 \%\left(33,000 \mathrm{~g} \cdot \mathrm{mol}^{-1}\right)$. This figure has been reprinted with permission from Riehle et al. ${ }^{48}$. Please click here to view a larger version of this figure.

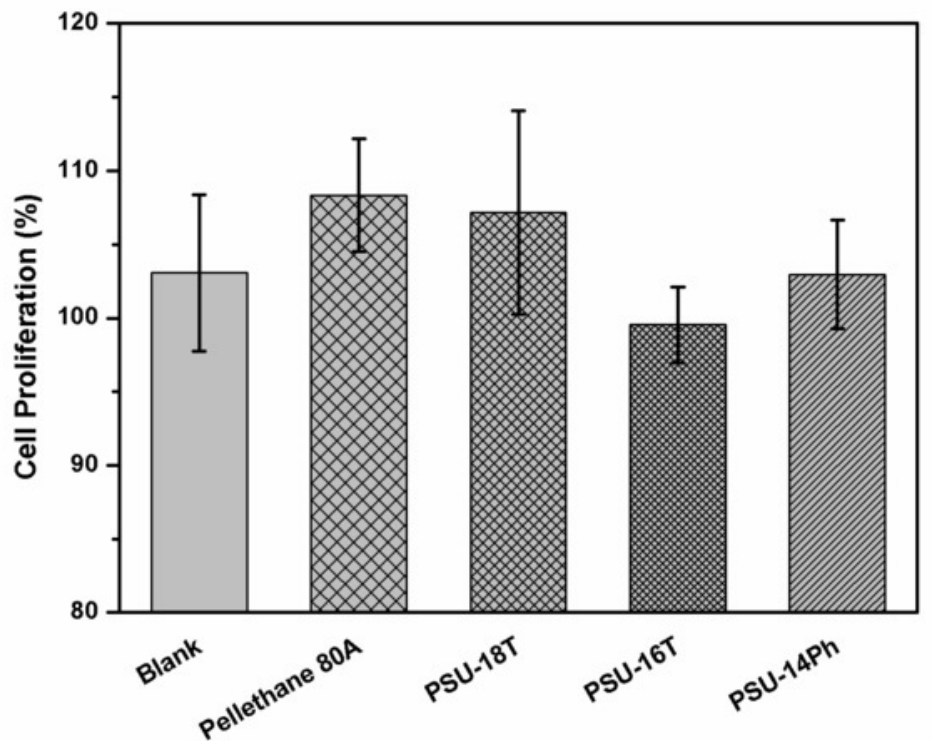

Figure 12: Results of in vitro cytotoxicity tests on HaCaT cells treated with PSU extracts. This figure shows the cell proliferation of the $\mathrm{HaCaT}$ cells treated with the cell medium extracts of PSU elastomers. The values are expressed as the mean value obtained from three tested extracts per sample, with six repeated measurements for each extract (18 replicates in total). The error bars represent the standard deviation from these measurements. The blank represents the cell medium DMEM (without the sample), which was treated analogous to the cell medium used for extraction. A medical-grade polyether urethane was selected as the reference material. Silicone-based polyurea elastomers (PSU-18T, PSU-16T, and PSU-14Ph) were selected as representative test samples, which were based on PDMS with molecular weights of 18,000 and $16,000 \mathrm{~g} \cdot \mathrm{mol}^{-1}$ (PSU-18T and PSU-16T), whereas PSU-14Ph was based on a polydimethyl-methyl-phenyl-siloxane-copolymer with 14 mol\% of methyl-phenyl-siloxane and a molecular weight of $\sim 16,600 \mathrm{~g} \cdot \mathrm{mol}^{-1}$. The mean proliferation of HaCaT cells, treated with the extracts of the PSU elastomers, and the reference polyurethane was $100 \%$ and higher. Therefore, the extracts of the PSU elastomers and reference polyurethane are not cytotoxic. Please click here to view a larger version of this figure. 


\section{Discussion}

To achieve high-molecular-weight aminopropyl-terminated PDMS via ring-chain equilibration, using an anhydrous, strongly basic catalyst is crucial. Other typically applied catalysts, such as tetramethylammonium hydroxide (TMAH) or potassium hydroxide $(\mathrm{KOH})$, contain water residues, which promote side reactions; hence, a mixture of difunctional, monofunctional, and nonfunctional PDMS chains with similar molecular weights is obtained ${ }^{44}$. Furthermore, if TMAH is used, the reaction requires $>48 \mathrm{~h}$ for completion and does not always proceed with complete monomer consumption ${ }^{44}$.

In particular, the weighing of the endblocker APTMDS is critical to obtain the desired molecular weight of PDMS. For example, instead of $0.9 \mathrm{~g}$ of APTMDS, if $0.85 \mathrm{~g}$ is used to synthesize PDMS, as described in section 2.1 of the protocol, this would lead to a theoretical molecular weight of approximately $>900 \mathrm{~g} \cdot \mathrm{mol}^{-1}$. In addition, the theoretical molecular weight is dependent on the conversion. If the cyclic side products are not considerably removed via vacuum distillation, a high conversion value will be obtained. For example, to use the same synthesis procedure (as in section 2.1 of the protocol), a calculated conversion of $90 \%$ would lead to a theoretically calculated molecular weight; this value is $910 \mathrm{~g} \cdot \mathrm{mol}^{-1}$ greater than that if a conversion of $85 \%$ is presumed. Deviations in the polysiloxane molecular weight determination by titration are possibly related to the weighing of PDMS into the flasks, particularly if a $50 \mathrm{~mL}$ burette is used for titration. A deviation related to the weighing of $0.06 \mathrm{~g}$ of polysiloxane might lead to a calculated difference of $\sim 650 \mathrm{~g} \cdot \mathrm{mol}^{-1}$. Hence, the use of a semiautomatic titrator is recommended.

The refractive index of PDMS can be increased by the incorporation of phenyl groups ${ }^{17,51}$, halogenated phenyl groups ${ }^{52}$, or sulfur-containing groups $^{53}$. Attempts to incorporate phenyl groups into PDMS via the copolymerization of octaphenylcyclotetrasiloxane $\left(D_{4}{ }^{\text {Ph }}\right)$ as described by Yilgör, Riffle, and McGrath ${ }^{54}$ were unsuccessful under the applied reaction conditions, possibly because the bulky ring backbone made it impossible for the applied catalyst to break up the siloxane bonds at the selected reaction temperature. The $\mathrm{D}_{4}{ }^{\mathrm{Ph}}$ ring can be opened if $\mathrm{KOH}$ is used at a reaction temperature of $160^{\circ} \mathrm{C}$. However, polysiloxanes of extremely high molecular weight are obtained, which presumably contain high amounts of nonfunctional impurities. In addition, the removal of the catalyst $\mathrm{KOH}$ in those copolymers is not straightforward and requires a neutralization step using ethanolic $\mathrm{HCl}$, followed by an aqueous extraction of the catalyst. Then, the PDMS has to be dissolved in an organic solvent, such as $\mathrm{CH}_{2} \mathrm{Cl}_{2}$, to separate the aqueous phase from the organic PDMS-containing phase. Finally, the organic phase must be dried over $\mathrm{MgSO}_{4}$, followed by filtration and vacuum distillation using a rotary evaporator ${ }^{54}$. In contrast, the method presented in this manuscript allows the catalyst to be removed immediately via thermal decomposition. Therefore, instead of using solid monomer $\mathrm{D}_{4}^{\mathrm{Ph}}$, phenyl groups are successfully introduced into the PDMS backbone by the copolymerization of the liquid monomer $\mathrm{D}_{4}{ }^{\mathrm{Me}, \mathrm{Ph}}$, as confirmed by ${ }^{29} \mathrm{Si}-\mathrm{NMR}$ spectroscopy ${ }^{50}$.

The synthesized PSU elastomers exhibited YM of 0.6 - 5.5 MPa and high elasticity with elongation values of up to $1,000 \%$. Such high elongation values were related not only to the polymer segmented structure but also to the high molecular weights of the PSU elastomers $\left(\bar{M}_{n}>100,000\right.$ $\left.\mathrm{g} \cdot \mathrm{mol}^{-1}\right)^{48}$. An instantaneous reaction occurs between the amino groups and aliphatic isocyanyate groups at room temperature, leading to rapidly increasing molecular weight. This result was further supported by conducting the reaction in a solvent, because a slight increase in viscosity did not appear to slow down the reaction speed significantly, which would otherwise dramatically affect the molecular weight for a nearly balanced stoichiometric ratio. In contrast, when a short chain diol, such as 1,4-butanediol, was used as the chain extender, the resulting polyurethane-urea elastomers were not only less elastic but also lost considerable mechanical stability, particularly if high-molecular-weight PDMS was used for synthesis. This result was presumably related to the considerably low molecular weights of the elastomers (results not published), corresponding to the incomplete conversion of all isocyanate groups at the last stage of polyaddition. In addition, differences in reactivity between the amino and hydroxyl groups toward aliphatic diisocyanates dramatically affected the results obtained from in vitro cytotoxicity tests. Extracts of the PSU elastomer prepared from the amino-chain extender APTMDS did not exhibit any cytotoxic effect on the HaCaT cells (Figure 12). However, if extracts of a siloxane-based polyurethane-urea elastomer were used, the cell viability was drastically reduced (results not published), which was possibly related to the low-molecular-weight leachables and residual unreacted isocyanate groups.

This protocol describes a convenient method for preparing amino-functional polysiloxanes, which can be subsequently used as macrodiamines for synthesizing high-molecular-weight, soft, and elastic polysiloxane-urea elastomers. As the mechanical properties of the PSUs can be varied according to the PDMS molecular weight, it is possible to use these polymers in other application fields. Furthermore, the procedure for preparing amino-functional polysiloxanes can be used for the introduction of side groups, such as vinyl groups, via the copolymerization of a cyclic siloxane with pendant vinyl groups (results not shown). This may open up new application fields, including the preparation of soft crosslinked polysiloxane gels (e.g., by Pt-catalyzed hydrosilylation with a hydride-functional silicone or by UV-activated thiol-ene addition of mercapto-functional PDMS) (results not shown).

\section{Disclosures}

The authors have nothing to declare.

\section{Acknowledgments}

The authors would like to thank the Federal Ministry of Education and Research (BMBF) for funding this work under grant number $13 \mathrm{FH} 032 \mathrm{I} 3$. Financial support by the Deutsche Forschungsgemeinschaft (DFG, Gepris project 253160297) is gratefully acknowledged. The authors further like to express their thanks to Priska Kolb and Paul Schuler from the University of Tübingen for performing ${ }^{1} \mathrm{H}-\mathrm{NMR}$ and ${ }^{29} \mathrm{Si}-\mathrm{NMR}$ measurements. Thanks are also due to CSC Jäkle Chemie $\mathrm{GmbH} \&$ Co. KG for their supply of $\mathrm{H}_{12} \mathrm{MDI}$. The authors would like to thank Herbert Thelen and André Lemme from Biotronik for performing ethylene oxide sterilization of the PSU samples and Lada Kitaeva (Reutlingen University) for her support with stress-strain and hysteresis measurements. 


\section{References}

1. Berman, E.R. Biochemistry of the Eye. Springer Science and Business Media. New York, NY (1991).

2. Bozukova, D., Pagnoulle, C., Jérôme, R., Jérôme, C. Polymers in modern ophthalmic implants-Historical background and recent advances. Materials Science and Engineering: R: Reports. 69 (6), 63-83 (2010).

3. Kohnen, T., Baumeister, M., Kook, D., Klaproth, O.K., Ohrloff, C. Kataraktchirurgie mit Implantation einer Kunstlinse. Deutsches Ärzteblatt International. 106 (43), 695-702 (2009).

4. Lace, R., Murray-Dunning, C., Williams, R. Biomaterials for ocular reconstruction. Journal of Materials Science. 50 (4), $1523-1534$ (2015).

5. Ong, H.S., Evans, J.R., Allan, B.D.S. Accommodative intraocular lens versus standard monofocal intraocular lens implantation in cataract surgery. Cochrane Database of Systematic Reviews. (5), 1-44 (2014).

6. Sheppard, A.L., Bashir, A., Wolffsohn, J.S., Davies, L.N. Accommodating intraocular lenses: a review of design concepts, usage and assessment methods. Clinical and Experimental Optometry. 93 (6), 441-452 (2010).

7. Menapace, R., Findl, O., Kriechbaum, K., Leydolt-Koeppl, C. Accommodating intraocular lenses: a critical review of present and future concepts. Graefe's Archive for Clinical and Experimental Ophthalmology. 245 (4), 473-489 (2007).

8. Dick, H.B. Accommodative intraocular lenses: current status. Current Opinion in Ophthalmology. 16 (1), 8-26 (2005).

9. De Groot, J.H. et al. Hydrogels for an Accommodating Intraocular Lens. An Explorative Study. Biomacromolecules. 4 (3), $608-616$ (2003).

10. Nishi, O. et al. Refilling the lens with an inflatable endocapsular balloon: surgical procedure in animal eyes. Graefe's Archive for Clinical and Experimental Ophthalmology. 230 (1), 47-55 (1992).

11. Nishi, O., Nishi, K. Accommodation amplitude after lens refilling with injectable silicone by sealing the capsule with a plug in primates. Archives of Ophthalmology. 116 (10), 1358-1361 (1998).

12. Nishi, O., Nishi, K., Mano, C., Ichihara, M., Honda, T. Lens refilling with injectable silicone in rabbit eyes. Journal of Cataract \& Refractive Surgery. 24 (7), 975-982 (1998).

13. Nishi, O., Nakai, Y., Mizumoto, Y., Yamada, Y. Capsule opacification after refilling the capsule with an inflatable endocapsular balloon. Journa of Cataract \& Refractive Surgery. 23 (10), 1548-1555 (1997).

14. Koopmans, S.A. et al. Accommodative Lens Refilling in Rhesus Monkeys. Investigative Ophthalmology \& Visual Science. 47 (7), $2976-2984$ (2006).

15. de Groot, J.H. et al. Injectable intraocular lens materials based upon hydrogels. Biomacromolecules. 2 (3), 628-634 (2001).

16. Hao, X. et al. Functionalised polysiloxanes as injectable, in situ curable accommodating intraocular lenses. Biomaterials. 31 (32), 8153-8163 (2010).

17. Hao, X. et al. High refractive index polysiloxane as injectable, in situ curable accommodating intraocular lens. Biomaterials. 33 (23), 5659-5671 (2012)

18. Han, Y.K. et al. In vitro and in vivo study of lens refilling with poloxamer hydrogel. British Journal of Ophthalmology. 87, 1399-1402 (2003).

19. Glasser, A. Accommodation: Mechanism and Measurement. Ophthalmology Clinics. 19 (1), 1-12 (2006).

20. Glasser, A. Restoration of accommodation. Current Opinion in Ophthalmology. 17 (1), 12-18 (2006)

21. Tomas-Juan, J., Murueta-Goyena, L.A. Axial movement of the dual-optic accommodating intraocular lens for the correction of the presbyopia: Optical performance and clinical outcomes. Journal of Optometry. 8 (2), 67-76 (2015).

22. McLeod, S.D., Vargas, L.G., Portney, V., Ting, A. Synchrony dual-optic accommodating intraocular lens: Part 1: Optical and biomechanical principles and design considerations. Journal of Cataract \& Refractive Surgery. 33 (1), 37-46 (2007).

23. McDonald, J.P. et al. Sarfarazi Elliptical Accommodating IntraOcular Lens (EAIOL) in Rhesus Monkey Eyes In Vitro and In Vivo. Investigative Ophthalmology \& Visual Science. 44 (13), 256-256 (2003).

24. Ossma, I.L. et al. Synchrony dual-optic accommodating intraocular lens: Part 2: Pilot clinical evaluation. Journal of Cataract \& Refractive Surgery. 33 (1), 47-52 (2007).

25. Alio, J.L., Plaza-Puche, A.B., Montalban, R., Ortega, P. Near visual outcomes with single-optic and dual-optic accommodating intraocular lenses. Journal of Cataract Refractive Surgery. 38 (9), 1568-1575 (2012).

26. Chen, Q., Liang, S., Thousas, G.A. Elastomeric biomaterials for tissue engineering. Progress in Polymer Science. 38, 584-671 (2013).

27. Ward, R.S., Jones, R.L. Polyurethanes and Silicone Polyurethane Copolymers. In: Comprehensive Biomaterials. Edited by Ducheyne, P., 431-477, Elsevier Science (2011).

28. Yoda, R. Elastomers for biomedical applications. Journal of Biomaterials Science, Polymer Edition. 9 (6), 561-626 (1998).

29. Nicolson, P.C., Vogt, J. Soft contact lens polymers: an evolution. Biomaterials. 22 (24), 3273-3283 (2001).

30. Adhikari, R., Gunatillake, P.A., McCarthy, S.J., Meijs, G.F. Mixed macrodiol-based siloxane polyurethanes: effect of the comacrodiol structure on properties and morphology. Journal of Applied Polymer Science. 78 (5), 1071-1082 (2000).

31. Sheth, J.P. et al. Structure-property behavior of poly(dimethylsiloxane) based segmented polyurea copolymers modified with poly(propylene oxide). Polymer. 46 (19), 8185-8193 (2005).

32. Yilgor, I., Yilgor, E. Silicone-urea copolymers modified with polyethers. ACS Symposium Series. 964 (Science and Technology of Silicones and Silicone-Modified Materials), 100-115 (2007).

33. Elast-Eon ${ }^{T M}$ biocompatible polyurethane - CSIROpedia. https://csiropedia.csiro.au/elast-eon-biocompatible-polyurethane/. January 8,2018 (2008).

34. Gunatillake, P.A., Meijs, G.F., McCarthy, S.J., Adhikari, R. Poly(dimethylsiloxane)/poly(hexamethylene oxide) mixed macrodiol based polyurethane elastomers. I. Synthesis and properties. Journal of Applied Polymer Science. 76 (14), 2026-2040 (2000).

35. Adhikari, R., Gunatillake, P.A., McCarthy, S.J., Meijs, G.F. Low-modulus siloxane-based polyurethanes. I. Effect of the chain extender 1,3bis(4-hydroxybutyl)1,1,3,3-tetramethyldisiloxane (BHTD) on properties and morphology. Journal of Applied Polymer Science. 83 (4), $736-746$ (2002).

36. Adhikari, R., Gunatillake, P.A., McCarthy, S.J., Bown, M., Meijs, G.F. Low-modulus siloxane-polyurethanes. Part II. Effect of chain extender structure on properties and morphology. Journal of Applied Polymer Science. 87 (7), 1092-1100 (2003).

37. Martin, D.J. et al. Polydimethylsiloxane/polyether-mixed macrodiol-based polyurethane elastomers: biostability. Biomaterials. 21 (10), 1021-1029 (2000). 
38. Simmons, A. et al. Long-term in vivo biostability of poly(dimethylsiloxane)/poly(hexamethylene oxide) mixed macrodiol-based polyurethane elastomers. Biomaterials. 25 (20), 4887-4900 (2004).

39. Gunatillake, P.A., Martin, D.J., Meijs, G.F., McCarthy, S.J., Adhikari, R. Designing biostable polyurethane elastomers for biomedical implants. Australian Journal of Chemistry. 56 (6), 545-557 (2003).

40. Briganti, E. et al. Silicone based polyurethane materials: a promising biocompatible elastomeric formulation for cardiovascular applications. Journal of Materials Science: Materials in Medicine. 17 (3), 259-266 (2006).

41. Lim, F., Buchko, C., Shah, A., Simhambhatla, M. Medical device formed of silicone-polyurethane. U.S. Patent Application 09/879,023. (2002).

42. Ward, R., Anderson, J., McVenes, R., Stokes, K. In vivo biostability of polysiloxane polyether polyurethanes: Resistance to biologic oxidation and stress cracking. Journal of Biomedical Materials Research Part A. 77A (3), 580-589 (2006).

43. Hermans, E.A. et al. Development of a ciliary muscle-driven accommodating intraocular lens. Journal of Cataract \& Refractive Surgery. $\mathbf{3 4}$ (12), 2133-2138 (2008).

44. Hoffman, J.J., Leir, C.M. Tetramethylammonium 3-aminopropyl dimethylsilanolate-A new catalyst for the synthesis of high purity, high molecular weight $\alpha, \omega$-bis(aminopropyl) polydimethylsiloxanes. Polymer International. 24, 131-138 (1991).

45. Keiper, F. DIN 53504. Prüfung von Kautschuk und Elastomeren - Bestimmung von Reißfestigkeit, Zugfestigkeit, Reißdehnung und Spannungswerten im Zugversuch. Deutsches Institut für Normung e.V. (2017).

46. Wenzelewski, K. DIN EN ISO 10993-5. Biologische Beurteilung von Medizinprodukten - Teil 5: Prüfungen auf In-vitro-Zytotoxizität (ISO 10993-5:2009); Deutsche Fassung EN ISO 10993-5:2009. Deutsches Institut für Normung e.V. (2009).

47. Promega. CellTiter $96 \circledR A Q_{\text {ueous }}$ One Solution Cell Proliferation Assay. Technical Bulletin. https://www.promega.com/-/media/files/resources/ protocols/technical-bulletins/0/celltiter-96-aqueous-one-solution-cell-proliferation-assay-system-protocol.pdf (2012).

48. Riehle, N. et al. Influence of PDMS molecular weight on transparency and mechanical properties of soft polysiloxane-urea-elastomers for intraocular lens application. European Polymer Journal. 101, 190-201 (2018).

49. Gottlieb, H.E., Kotlyar, V., Nudelman, A. NMR Chemical Shifts of Common Laboratory Solvents as Trace Impurities. Journal of Organic Chemistry. 62 (21), 7512-7515 (1997).

50. Riehle, N., Götz, T., Kandelbauer, A., Tovar, G.E.M., Lorenz, G. Data on the synthesis and mechanical characterization of polysiloxane-based urea-elastomers prepared from amino-terminated polydimethylsiloxanes and polydimethyl-methyl-phenyl-siloxane-copolymers. Data in Brief. 18, 1784-1794 (2018)

51. Christ, R., Nash, B.A., Petraitis, D.J. Optically clear reinforced silicone elastomers of high optical refractive index and improved mechanical properties for use in intraocular lenses. U.S. Patent 5494946 A. (1993).

52. Jha, G.S., Seshadri, G., Mohan, A., Khandal, R.K. Sulfur containing optical plastics and its ophthalmic lenses applications. e-Polymers. 8 (1), 376-402 (2008).

53. Rogulska, M., Kultys, A., Olszewska, E. New thermoplastic poly(thiourethane-urethane) elastomers based on hexane-1,6-diyl diisocyanate (HDI). Journal of Thermal Analysis and Calorimetry. 114 (2), 903-916 (2013).

54. Yilgör, I., Riffle, J.S., McGrath, J.E. Reactive Siloxane Oligomers. In: Reactive Oligomers. Edited by Harris, F.W., Spinelli, H.J., 161-174, American Chemical Society. Washington, DC (1985). 